\title{
Prevalence of Multiple Sclerosis in Barrhead County, Alberta, Canada
}

\author{
Sharon Warren and K.G. Warren
}

\begin{abstract}
A prevalence study of multiple sclerosis (MS) was carried out in the town of Barrhead and surrounding county of Barrhead, in Alberta, Canada. The prevalence rate for clinically probable/definite multiple sclerosis on January 1, 1990 was 196/100,000. The average annual incidence rates for patients living in the area at onset were $1.31 / 100,000$ for $1950-59,4.97 / 100,000$ for $1960-69,3.77 / 100,000$ for $1970-79$, and $4.22 / 100,000$ for $1980-89$. Fifty per cent of the patients were relapsing-remitting. Sixty per cent were still walking without assistance. The female-tomale ratio was 1:1. Mean current age, age at onset and duration of illness were 49,27 and 22 years respectively. The majority of patients $(40 \%)$ experienced multiple symptom onset. Fifty per cent were of single ethnic origin (either British or German); the rest were predominantly North European combinations. Forty per cent of patients reported another MS relative. MS had affected the work status of $60 \%$ of the patients, $15 \%$ of whom were confined to an extended care centre.
\end{abstract}

\begin{abstract}
RÉSUMÉ: Prévalence de la sclérose en plaques dans le compté de Barrhead, Alberta, Canada. Une étude de prévalence de la sclérose en plaques (SEP) été effectuée dans la ville de Barrhead et le comté avoisinant de Barrhead, en Alberta, au Canada. Le taux de prévalence pour la sclérose en plaques cliniquement probable/certaine au premier janvier 1990 était de 196/100,000. Les taux d'incidence annuels moyens pour les patients résidant dans la région au début de leur maladie étaient de $1.31 / 100,000$ pour $1950-59,4.97 / 100,000$ pour $1960-69,3.77 / 100,000$ pour 1970-79, et 4.22/100,000 pour 1980-89. Chez cinquante pourcent des patients, la maladie évoluait par poussées et rémissions. Soixante pourcent marchaient encore sans aide. La proportion femme:homme était de 1:1. L'âge moyen actuel, l'âge de début et la durée de la maladie étaient de 49,27 et 22 ans respectivement. La majorité des patients (40\%) avaient présenté des symptômes multiples comme mode de début de leur maladie. Cinquante pourcent étaient d'origine ethnique unique (soit britanniques ou allemands); les autres étaient en majorité d'une combinaison d'origines ethniques de l'Europe du nord. Quarante pourcent des patients ont rapporté qu'ils avaient un membre de leur famille qui était également atteint de SEP. La SEP a perturbé l'emploi de $60 \%$ des patients et $15 \%$ de ceux-ci résidaient dans un centre de soins prolongés.
\end{abstract}

Can. J. Neurol. Sci. 1992; 19:72-75

Canada is generally recognized as a high-risk zone for multiple sclerosis (MS). Prevalence rates per 100,000 have been reported for several provinces. They include: 25 for Halifax, ${ }^{1}$ Nova Scotia; 39 for Kingston, ${ }^{2} 67$ for Ottawa ${ }^{3}$ and 94 for London, ${ }^{4}$ Ontario; 35 for Winnipeg, ${ }^{5}$ Manitoba; 111 for Saskatoon, ${ }^{6}$ Saskatchewan; and 93 for the province of British Columbia. ${ }^{7}$ Until recently, there were no figures available for the province of Alberta. However, in 1990, Klein et al. ${ }^{8}$ reported a prevalence rate of $87 / 100,000$ in Cardston and 202/100,000 in Crows Nest Pass, both regions in southern Alberta. Based on prevalence rates in other parts of Canada, these researchers concluded that the Cardston rate of $87 / 100,000$ was probably typical for Alberta while Crows Nest Pass represents an area of excess risk.
The University of Alberta's MS Clinic has recently completed a study of the prevalence of MS in Barrhead County, which is northwest of Edmonton in central Alberta (Figure 1).

\section{Characteristics of Barrhead County}

Barrhead County is a rural area encompassing several small towns. One of these towns, Manola, is the geographic centre of Alberta with an approximate latitude of $54^{\circ}$ and a longitude of $114^{\circ}$. The major town is a separate municipality also called Barrhead. The county is located about 90 miles northwest of Edmonton, Alberta's capital. At the time of the 1986 census, the population of the county plus the town of Barrhead was 9,720 , $50 \%$ males $(\mathrm{N}=4,890)$ and $50 \%$ females $(\mathrm{N}=4,830)$. The population under age 20 was $34 \%(\mathrm{~N}=3,345), 20-64$ was $54 \%(\mathrm{~N}=$

From the Faculty of Rehabilitation Medicine (S.W.), and the Multiple Sclerosis Patient Care and Research Clinic (K.G.W.), University of Alberta, Edmonton, Alberta, Canada

Received April 18, 1991. Accepted in final form July 25, 1991

Reprint requests to: Sharon Warren, Ph.D., Associate Professor, Faculty of Rehabilitation Medicine, Room 329, Corbett Hall, University of Alberta, Edmonton, Alberta, Canada T6G 2G4 
$5,200)$, and over 65 was $12 \%(\mathrm{~N}=1,175)$. Among people with single ethnic origins, $23 \%$ were British, $21 \%$ German, $10 \%$ Dutch, and $8 \%$ other. The remaining $38 \%$ of the population were of multiple ethnic origins, predominantly British and North European combinations. ${ }^{9}$

There are 9 general practitioners within the community, but no neurologists. The University of Alberta's Multiple Sclerosis Patient Care and Research Clinic, located in Edmonton, is the primary referral centre for suspected/diagnosed MS patients in north-central Alberta, with a patient list in excess of 2,100.

\section{Methons}

The records of the University of Alberta's MS Clinic were searched to identify all patients whose address was in Barrhead County. General practitioners in the area were requested to contact their MS patients for permission to provide their names to the study's research team. The county's one general hospital, one nursing home, local public health clinic, and the Barrhead County chapter of the MS Society, were asked to follow the same procedure. The resulting lists were combined and duplicate names eliminated. All of these resources cooperated fully, and none reported approaching a patient who refused to participate.

All non-hospitalized patients were asked to visit the local public health clinic for a neurological examination, and to provide some basic information on personal and disease characteristics. Hospitalized patients were visited in the facility where they resided. The neurological examination was conducted by the director of the University of Alberta's MS Clinic. Patients were rated as possible, probable or definite according to Poser's scoring system. ${ }^{10}$ Their disease course was classified as: relaps-

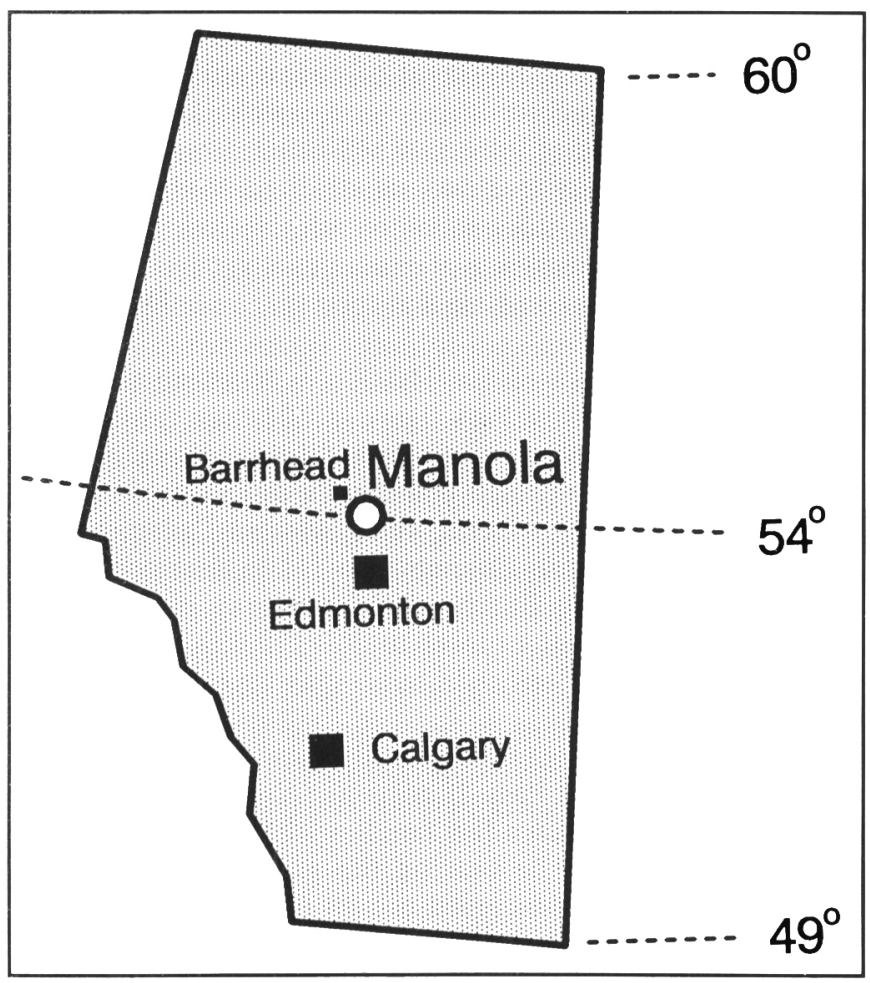

Figure 1-Location of study area. ing-remitting; relapsing-remitting at onset, but having become chronic progressive; and chronic progressive from onset. The Kurtzke Disability Status Scale ${ }^{11}$ was used to assign patients a disability rating from 1-10. Information was collected on: gender; current age; age at onset; residence at time of onset; initial symptom; duration of illness; ethnic origin; and family history of MS. Some data regarding the impact of the disease, for example, on employment status and living arrangements, were also recorded.

The prevalence date was set as January 1, 1990, and all data were collected between this date and April 30, 1990. Only residents of Barrhead County who were alive on January 1, 1990, and had resided in the county for at least 1 year, were included in prevalence estimates. Patients who were being examined by the director of the MS Clinic for the first time were included if their diagnosis was confirmed, and there was accurate documentation that the onset of MS was prior to January 1, 1990.

\section{RESULTS}

There were 15 patients from Barrhead County on file with the University of Alberta's MS Clinic. Six additional patients were identified from other resources. One patient from the MS Clinic had died since January 1, 1990, but was included using her file information. All of the rest were evaluated directly. Only 1 person, referred from another resource, was excluded because symptom onset was relatively recent and there was insufficient evidence to confirm the diagnosis. This left a total of $20 \mathrm{MS}$ patients, all of whom had lived in Barrhead County for at least one year.

\section{Prevalence}

Table 1 shows the MS cases and crude point prevalence rate for probable/definite patients, using the 1986 total population of Barrhead County as the denominator. Of the 20 patients identified, 1 was classified as possible, 4 probable and 15 definite. Using only probable/definite cases, the prevalence rate was cal-

Table 1: Overall, Sex and Age Specific MS Prevalence Rates for Barrhead County, Alberta, January 1, 1990

\begin{tabular}{lcccr}
\hline \hline & Cases & Population' & $\begin{array}{c}\text { Rate per } \\
\mathbf{1 0 0 , 0 0 0}\end{array}$ & CI's $^{2}$ \\
\hline Overall & 19 & 9,720 & 196 & $118-305$ \\
& & & & \\
Sex - Specific & & & & \\
$\quad$ Female & 10 & 4,830 & 207 & $99-381$ \\
Male & 9 & 4,890 & 184 & $84-349$ \\
& & & & \\
Age - Specific & & & & \\
Under 20 & - & 3,345 & - & - \\
$20-24$ & - & 715 & - & - \\
$25-34$ & 2 & 1,465 & 137 & $17-495$ \\
$35-44$ & 8 & 1,185 & 675 & $291-1330$ \\
$45-54$ & 2 & 965 & 207 & $25-747$ \\
$55-64$ & 6 & 870 & 690 & $253-1504$ \\
$65+$ & 1 & 1,175 & 85 & $2-473$ \\
\hline
\end{tabular}

1 Taken from Statistics Canada census of Alberta for 1986.

$295 \%$ confidence intervals. 
culated to be $196 / 100,000$, with a $95 \%$ confidence interval (CI) from 118 to 305 when the Poisson distribution is applied. If the possible case was included, the rate would become $206 / 100,000$ (CI's $=126$ to 317). The CI's are wide for these and the following rates because of the small number of patients on which they are based. Although this affects generalization to Alberta, the rates for Barrhead County can only be underestimates.

Table 1 also shows the sex and age-specific rates for Barrhead County. Of the 19 probable/definite cases, 10 were female and 9 male, giving prevalence rates of $207 / 100,000(\mathrm{CI}=$ 99 to 381$)$ and $184 / 100,000(\mathrm{CI}=84$ to 349$)$ respectively. There were no patients under age 25 ; the rate for 25-64-year-old patients was $346 / 100,000(\mathrm{CI}=205$ to 547$)$ and for $65+$ patients $85 / 100,000(\mathrm{CI}=2$ to 473$)$.

\section{Incidence}

Table 2 shows the average annual incidence rates by decade from $1950 \mathrm{on}$, using only probable/definite MS patients who reported living in Barrhead County at the time of onset $(\mathrm{N}=$ 12). These were $1.31(\mathrm{CI}=.03-7.28)$ for $1950-59,4.97(\mathrm{CI}=$ $1.35-12.72)$ for $1960-69 ; 3.77(\mathrm{CI}=.78-11.02)$ for $1970-79$, and $4.22(\mathrm{CI}=1.15-10.80)$ for $1980-89$. The possible case was also living in Barrhead County when suspicious symptoms occurred in the 1950's, which would bring the incidence rate for that decade to $2.61(\mathrm{CI}=1.31-9.42)$. Since some persons who originally developed MS in Barrhead County may have left the area before this study was conducted, these incidence rates may be underestimates.

\section{Patient and Disease Characteristics}

Disease course, disability status and other patient characteristics were summarized including the patient with a possible diagnosis. Ten patients $(50 \%)$ had experienced a relapsing-remitting disease course; 9 had begun with relapsing-remitting disease and become chronic progressive; and 1 had been chronic progressive from onset. Twelve patients $(60 \%)$ were still walking without assistance (i.e. scored 5 or less on the Kurtzke scale).

Half of the patients were female $(50 \%, N=10)$, for a male-to female ratio of $1: 1$. Patients' mean current age was $48.8( \pm$ 11.5). Their mean age at onset was 27.4 ( \pm 6.9$), 3$ had had onset between ages $10-19$ and 1 later than age 40 .

Twelve of the 20 patients $(60 \%)$ were living in Barrhead County at the time of onset. Three were living in an adjacent county within a few miles of the Barrhead County line, 1 was visiting back and forth between Edmonton and Barrhead. Three

Table 2: Average Annual MS Incidence Rates by Decade from 1950 on, for Barrhead County, Alberta

\begin{tabular}{lcccr}
\hline \hline & Cases & $\begin{array}{c}\text { Average } \\
\text { Population }\end{array}$ & $\begin{array}{c}\text { Rate per } \\
\mathbf{1 0 0 , 0 0 0}\end{array}$ & \multicolumn{1}{c}{ CI's $^{2}$} \\
\hline $1950-59$ & 1 & 7,649 & 1.31 & $.03-7.28$ \\
$1960-69$ & 4 & 8,052 & 4.97 & $1.35-12.72$ \\
$1970-79$ & 3 & 7,962 & 3.77 & $.78-11.02$ \\
$1980-89$ & 4 & 9,486 & 4.22 & $1.15-10.80$ \\
\hline
\end{tabular}

1 Taken from Statistics Canada census of Alberta, average population for years: 1951 and 1956; 1961 and 1966; 1971 and 1976; 1981 and 1986.

$295 \%$ confidence intervals. other patients were living elsewhere in another Canadian province and 1 was in Europe.

As for initial symptom, 5 patients reported visual symptoms, 1 motor, 6 sensory and $8(40 \%)$ a combination of the above.

Patients' mean duration of illness was 21.7 years $( \pm 11.0)$ with a range from 4 to 52 .

Ten patients $(50 \%)$ were of a single ethnic origin, (7 British and 3 German). The remainder were of multiple origins, predominantly north European combinations.

\section{MS Family History}

Eight of the 20 patients (40\%) reported at least one other relative with multiple sclerosis, for a total of 10 . Seven of these patients (35\%) reported close relationships (i.e. first, second and third degree): 1 mother, 5 sisters, 2 aunts and 1 niece. One patient had a great aunt with MS. Another patient had an aunt in a wheelchair from an undiagnosed illness, but this relative was not counted as evidence of a positive history.

\section{Impact of MS}

MS had affected the work status of a majority of patients $(60 \%)$. Of the 20 patients interviewed, 10 had stopped working outside the home, and 2 had curtailed work, because of MS. On the other hand, 5 patients were still working full-time; another 2 were working part-time and 1 was unemployed, by choice not due to MS. The majority of patients $(85 \%)$ were living independently in the community. Three required a level of care which had resulted in their being placed in the local nursing home, and precluded employment. The deceased patient was one of those who had been institutionalized as of the prevalence date.

\section{Discussion}

Because Barrhead County is a small, well-defined geographical area, case ascertainment is likely to be relatively complete, especially considering the level of cooperation from local resources. Since all recorded cases were examined by the director of the University of Alberta's MS Clinic, confirmation of diagnosis and disability level was standardized. With all patients agreeing to cooperate, information on other factors like disease course, age at onset, residence at onset, initial symptom, and MS family history was as complete and accurate as can be expected with self-report.

The prevalence rate of $196 / 100,000$ in Barrhead County is closer to the Crows Nest Pass figure of 202 than the Cardston figure of 87 , reported by Klein et al.$^{8}$ for southern Alberta. These researchers concluded that the Cardston rate was more likely to be typical of Alberta, since Western Canadian rates range from 93 in British Columbia ${ }^{7}$ to 111 in Saskatoon. ${ }^{6}$ The rate of 196 found in Barrhead County may indicate that Alberta's rate is actually closer to $200 / 100,000$, or that both Crows Nest Pass and Barrhead County may have atypically high rates.

Klein et al. have suggested several explanations for the high rate in the Crows Nest Pass. If areas like Crows Nest Pass and Barrhead County contain a few families who are predisposed to MS, then this might be biasing the prevalence data. The Barrhead County cases included one set of sisters. None of the other cases were related.

Klein et al. note that in the past 10 years, Crows Nest Pass has been economically depressed. The migration of healthy 
young people out of the area, leaving behind elderly and infirm, could create a false impression of very high prevalence. In Barrhead County, $48 \%$ of the population was either under the age of 19 or over 65 , which is not unlike the distribution noted in recent studies of Saskatoon ${ }^{6}$ and London, Ontario. ${ }^{4}$ Some health care researchers have conversely suggested that the disabled are more likely to move to large urban areas because of the greater variety of services available there, which might mean that the Barrhead figures are actually an underestimate.

Finally, as Klein et al. recognize, the Crows Nest Pass prevalence rate may reflect a true excess risk, as might the Barrhead County rate. Crows Nest Pass has long been reputed to be high risk for MS. Barrhead County has a very active MS Society chapter, based on the self-perception that it is a high risk area. The investigators were aware of this perception prior to conducting the study and recognize that the results may confirm the MS Society chapter's impression of an excess risk in Barrhead County. If both areas are high risk, the identification of commonalities between them might suggest etiological factors which increase the risk of developing MS. In Crows Nest Pass, 9 of the 14 identified cases had spent most of their lives in that area. Sixteen of the 20 patients in this study had lived in Barrhead or an adjacent county prior to onset, and 11 of them had spent most of their lives in the area. These figures support the position that some aspect of the local environment, which is a risk factor for MS, may be more common in Barrhead County than other parts of Alberta or Canada. Although based on small numbers, the incidence rate pattern in Barrhead County indicates a constant environmental risk factor, not a point epidemic.

Patient and disease characteristics among Barrhead cases are somewhat different from those described in other Canadian studies during the past decade, ${ }^{4,6,7}$ notably on the ratio of females-to-males and on MS family history. Females typically outnumber males, with female-to-male ratios of 1.94:1 reported in Saskatoon, ${ }^{6} 2.2: 1$ in London, ${ }^{4}$ and 2.1:1 in British Columbia; ${ }^{7}$ but, in Barrhead County, the ratio is $1: 1$. As for MS family history, in Saskatoon, ${ }^{6}$ only $15.3 \%$ of MS patients reported a close family member with MS, and $14.4 \%$ in London, Ontario. ${ }^{4}$ The highest estimate reported in the literature appears to be $22.5 \%,{ }^{12}$ while $35 \%$ of Barrhead patients reported a close family member with MS. Even taking into account the two sisters among these patients, this percentage seems to indicate an excess. The diagnosis was not verified in patients' relatives (with the exception of the two cases who were sisters). However, most were close relatives, so that reporting may have been reasonably accurate. No data were collected on whether any of the patients' relatives had ever lived in Barrhead County. If several of them had lived there prior to onset, it would strengthen the position that Barrhead County is an area of excess risk, since these relatives might have experienced common exposure to a local factor.

Current thinking holds that people who are genetically susceptible to multiple sclerosis and encounter a causal, environmental factor will experience an autoimmune reaction which results in demyelination of the central nervous system. Whether the $196 / 100,000$ prevalence rate in Barrhead County is representative of Alberta or indicates that the area is at excess risk due to genetic or environmental factors, this rate is among the highest reported worldwide. It is almost twice the average rate of $100 / 100,000$ observed in the northern United States ${ }^{13}$ and Canada, ${ }^{1-8}$ with the only comparable rates coming from Scotland's Orkney Islands $(258 / 100,000)$ and Shetland Islands $(152 / 100,000) .{ }^{14}$ Further studies may be required to clarify the typical MS prevalence rate in Alberta.

\section{ACKNOWLEDGEMENTS}

We would like to thank the following doctors for their cooperation: Dr. Charles V. Godberson, Dr. Edward T. Kallal, Dr. Marvin B. Wray, Dr. John H.S. Empey, Dr. Jeffrey J. Hankinson, Dr. Dhanji Lalji, and Dr. Louise S. Matthews. We would also like to thank Mr. Howard Lawson, Administrator of the Barrhead General Hospital and the Keir Extended Care Centre; Ms. Diana DeGroot of the Barrhead County Health Unit; Mrs. Gertie Gerth, Barrhead Chapter of the MS Society; Mr. T. Greg Birch of the Yellowhead Regional Planning Commission Ms. Joyce Properzi for organizing and coordinating the interviews; and Ms. Lillian Bas for her research and secretarial assistance.

\section{REFERENCES}

1. Alter M, Allison RS, Talbert OR, et al. Geographic distribution of multiple sclerosis. World Neurol 1960; 1: 55-70.

2. White DN, Wheelan L. Disseminated sclerosis: a survey of patients in the Kingston, Ontario area. Neurology 1959; 9: 256-272.

3. Bennett L, Hamilton R, Neutel CI, et al. Survey of persons with multiple sclerosis in Ottawa, 1974-1975. Can J Public Health 1976; 68: 141-147.

4. Hader WJ, Elliot M, Ebers GC. Epidemiology of multiple sclerosis in London and Middlesex County, Ontario, Canada. Neurology 1988; 38: 617-620.

5. Stazio A, Kurland LT, Bell LG, et al. Multiple sclerosis in Winnipeg, Manitoba: methodological considerations of epidemiologic survey. Ten year follow-up of a community wide study, and population re-survey. J Chronic Dis 1964; 17: 415-438.

6. Hader WJ. Prevalence of multiple sclerosis in Saskatoon. Can Med Assoc J 1982; 127: 295-297.

7. Sweeny VP, Sadovnick AD, Brandejs V. Prevalence of multiple sclerosis in British Columbia. Can J Neurol Sci 1986; 13:47-51.

8. Klein GM, Seland TP, Barclay L, et al. An epidemiologic study of multiple sclerosis in the Crows Nest Pass and Cardston regions of southern Alberta. Can J Neurol Sci 1990; 17: 241.

9. Statistics Canada - 1988. 1986 Census of Canada, Alberta: Part 2, Census Divisions and Subdivisions.

10. Poser CM. A numerical scoring system for the classification of multiple sclerosis. Acta Neurol Scand 1979; 60: 100-111.

11. Kurtzke JF. Further notes on disability evaluation in multiple sclerosis with scale modifications. Neurology $1965 ; 15: 654-661$.

12. Sandovnick AD, Macleod PMJ. The familial incidence of multiple sclerosis: empiric recurrence risks for first, second and third degree relatives of patients. Neurology 1981; 31: 1039-1041.

13. Kurtzke JF, Kurland LT. General overview of the epidemiology of multiple sclerosis. In: Kuroiwa Y, Kurland LT, eds. Multiple sclerosis, east and west. Fukuoka: Kyushu University Press, $1982 ; 3-29$.

14. Poskanzer DC, Walker AM, Yonkondy J, et al. Studies in the epidemiology of multiple sclerosis in the Orkney and Shetland Islands. Neurology (Minneap) 1976; 26: 14-17. 